\title{
Desenho Universal para a Aprendizagem : criação e validação de um livro digital acessível
}

\author{
Fernando Henrique Bessa Marinho ${ }^{1}$, Flavia Faissal de Souza ${ }^{3}$, \\ Gustavo Henrique Sila Lima ${ }^{1}$, Luís Fernando Orleans ${ }^{1}$, \\ Márcia Denise Pletsch ${ }^{2}$, Márcia Marin ${ }^{4}$. Maria Antônia Goulart ${ }^{3}$, Patrícia Braun ${ }^{3}$ \\ 1 Universidade Federal Rural do Rio de Janeiro Instituto Multidisciplinar (UFRRJ-IM) \\ ${ }^{2}$ Programa de Pós-Graduação em Educação, Contextos Contemporâneos \\ e Demandas Populares (PPGEduc) - UFRRJ \\ ${ }^{3}$ Programa de Pós-Graduação de ensino em Educação Básica (PPGEB/UERJ) \\ ${ }^{4}$ Colégio Pedro II \\ Fernanadobessa@hotmail.com, dfaissalflavialgmail.com, drgustav1997@gmail.com \\ lforleans@ufrrj.br, marciadenisepletsch@gmail.com, marinvianna2014@gmail.com \\ goulart.mariaantoniaegmail.com, braunpatricia09egmail.com
}

\begin{abstract}
This article presents the concept of Universal Design for Learning $(U D L)$ that aims to meet the specifics of people who need support in their learning. In other words, it consists of designing, planning educational actions and artifacts that cater to as many individuals as possible, whether or not they are disabled. As proof of concept, a prototype of a digital textbook was created using the UDL concept, where the presentation of content is adapted according to the specific needs of the user. This prototype was tested with 21 children from 9 public schools of Baixada Fluminense in field activity, where its effectiveness was evaluated.
\end{abstract}

Resumo. Este artigo apresenta o conceito de Desenho Universal para Aprendizagem (DUA) que visa atender as especificidades de pessoas que necessitem de suporte em sua aprendizagem. Em outras palavras, consiste em projetar, planejar ações e artefatos pedagógicos que atendam ao maior número possível de indivíduos, sejam eles portadores de algum tipo de deficiência ou não. Como prova de conceito, foi criado um protótipo de um livro didático digital utilizando o conceito do DUA, onde a forma de apresentação do conteúdo se adapta de acordo com as necessidades específicas de quem o utiliza. Este protótipo foi testado com 21 crianças de 9 escolas públicas da Baixada Fluminense em atividade de campo, onde sua eficácia pôde ser avaliada.

\section{Introdução}

Com a implementação da Política Nacional de Educação Especial na Perspectiva da Educação Inclusiva [BRASIL 2008] e das Diretrizes Operacionais do Atendimento Educacional Especializado na Educação Básica, modalidade Educação Especial [BRASIL 2009], temos vivenciado diferentes mudanças no que diz respeito a 
VII Congresso Brasileiro de Informática na Educação (CBIE 2018)

Anais do XXIX Simpósio Brasileiro de Informática na Educação (SBIE 2018)

escolarização do público-alvo da Educação Especial (pessoas com deficiências intelectual, sensorial, transtornos globais do desenvolvimento e altas habilidades/superdotação).

Uma das mudanças com a implementação dessas diretrizes políticas diz respeito ao avanço das matriculas de pessoas com deficiência ao ensino comum. O maior número de matriculas, assim como em outras épocas históricas, é de pessoas com deficiência intelectual, seguidas pela deficiência física, baixa visão, auditiva, surdez e cegueira. Esses dados estão em acordo com os microdados analisados por [Mendes 2016], nos quais os alunos com deficiência intelectual concentram o maior número de matriculas, e somam ao todo cerca de $70 \%$ de todo o contingente de alunos público-alvo da Educação Especial.

Um conceito em que o estudo e desenvolvimento dessa pesquisa se baseam é o Desenho Universal na Aprendizagem (DUA) [Rose and Gravel 2010], esse pensamento elabora questões de acessibilidade, onde propõe suprir as especificidades de pessoas que apresentam alguma deficiência. Diante do exposto, foi implementado um protótipo de livro didático em formato digital que seguiu o protocolo DUA, podendo ser utilizado tanto por alunos que compõem o público-alvo da Educação Especial (cegos, deficiência intelectual, baixa visão, deficiência auditiva), e também crianças típicas. O protótipo foi validado com alunos de escolas públicas através de sessões de aplicação, onde foi verificada sua eficácia. De forma resumida, o protótipo do livro foi construído como uma página HTML onde, ao serem selecionadas as necessidades especiais de cada aluno, sua forma de exibição era alterada. Por fim, todos os dados de utilização do livro foram gravados para posterior análise e verificação de melhorias na apresentação do conteúdo.

\section{Diferenciação Curricular e Desenho Universal para Aprendizagem}

Diferenciação curricular diz respeito a modificações e estratégias organizadas pelos professores que tenham o objetivo de atender a demandas específicas dos alunos no processo de aprendizagem. No entanto, tais diferenciações não estão associadas á limitação, anulação ou ao empobrecimento dos conteúdos ou objetivos a serem propostos ao aluno; mas sim à revisão de estratégias e de recursos tecnológicos (de baixa ou alta tecnologia) usados para que o aluno com deficiência ou outras especificidades no desenvolvimento possa participar das propostas educacionais. Assim, "não se trata de elaborar um outro currículo e sim de trabalhar com o que for adotado, fazendo nele os ajustes necessários (flexibilização nos objetivos, conteúdos, metodologia de ensino, temporalidade, e nas práticas de avaliação da aprendizagem) de modo a oferecer a todos a verdadeira igualdade de oportunidades para construir conhecimentos". [CARVALHO 2008]

Aliado ao conceito de diferenciação curricular, empregamos o conceito de Desenho Universal para Aprendizagem (DUA) sustentado pela ideia do desenho universal, definido na Convenção sobre os Direitos da Pessoa com Deficiência [BRASIL 2009], como "concepção de produtos, ambientes, programas e serviços a serem usados, na maior medida possível, por todas as pessoas, sem necessidade de adaptação ou projeto específico" [Pletsch et al. 2017]. Em outras palavras, essa perspectiva não exclui as ajudas técnicas específicas, mas vai além da aplicação tradicional de acessibilidade aos espaços físicos, o uso de artefatos e produtos, recursos de comunicação e outros que visem a garantia de acesso e a participação de todas as pessoas, independentemente de suas especificidades sensoriais ou físicas visando, assim, condições plenas à locomoção, comunicação, informação e ao conhecimento. 
VII Congresso Brasileiro de Informática na Educação (CBIE 2018)

Anais do XXIX Simpósio Brasileiro de Informática na Educação (SBIE 2018)

O DUA cresceu a partir de conceitos de Desenho Universal (DU), originado na área de planejamento de Arquitetura e Urbanismo, como parte de um movimento para começar a projetar edifícios e outras estruturas para melhorar sua utilização, considerando, também, as pessoas com deficiência [SONDERMANN et al. 2013]. Segundo [SOUZA 2017], o DU foi elaborado nos anos de 1990 por Anne Meyer e David Rose no Centro de Tecnologia Especial Aplicada (CAST), e como dito anteriormente, com o objetivo de atender as especificidades de pessoas que apresentassem alguma deficiência. Atualmente, essa concepção sofreu avanços e, no contexto específico de aprendizagem, se aplica a qualquer artefato que é projetado para ser utilizado por pessoas com ou sem necessidades específicas. As diretrizes do DU indicam a customização de recursos e estratégias em sala de aula para efetivar a aprendizagem de todos.

\section{O Livro Digital}

\subsection{Conteúdo didático}

O livro Portas Abertas consta no Plano Nacional do Livro Didático (PNLD), que, por sua vez, é uma política educacional do Ministério da Educação (MEC), que tem por objetivo auxiliar professores da rede pública de educação através de distribuição de livros didáticos. Além disso, o livro Portas Abertas foi o mais distribuído nos PNLDs de 2010 e 2007 [CORNÉLIO 2015], e analisando essas informações, selecionamos um dos capítulos do livro, o capítulo 5 com a temática Ciências, como fonte para o desenvolvimento do protótipo do livro digital.

\subsection{Criação do Protótipo}

Conforme discutido anteriormente, o conceito DUA consiste em projetar e planejar ações e artefatos pedagógicos que atendam ao maior número possível de indivíduos, sejam eles portadores de algum tipo de deficiência ou não. Nesse contexto, foi desenvolvido um protótipo de um livro digital seguindo o conceito de Desenho Universal para Aprendizagem.

O livro digital foi projetado para ser uma página $H T M L$, com imagens, vídeos, trechos de código com JavaScript, entre outros, podendo, assim, ser possível utilizá-lo em qualquer dispositivo que ofereça um navegador $W e b$, como computadores convencionais, smartphones, e outros.

Um exemplo de uma questão contida no livro pode ser visto na Figura 1, onde é apresentado uma caixa de seleção contendo 9 figuras de 3 categorias diferentes (plantas, animais, pessoas), além da caixa de seleção, na figura também é apresentado uma outra caixa onde serão armazenadas as figuras de acordo com sua categoria.

\section{Aplicação do livro}

As equipes foram divididas em 4 grupos, onde cada grupo atendeu uma deficiência específica como mostrado na Tabela 1 . Nela, existem 4 colunas: a primeira exibe as deficiências que cada equipe atendeu, na coluna 2, a quantidade de escolas que cada equipe atendeu, na coluna 3, a quantidade de alunos cujo o livro foi aplicado, na coluna 4 quantos membros integraram cada equipe. Além disso, cada aplicador ficou responsável por um tablet onde foi disponibilizado o livro para fazer a aplicação. As equipes com maior índice de satisfação foram as de deficiência intelectual e autismo. Para estas, o livro foi 
VII Congresso Brasileiro de Informática na Educação (CBIE 2018)

Anais do XXIX Simpósio Brasileiro de Informática na Educação (SBIE 2018)

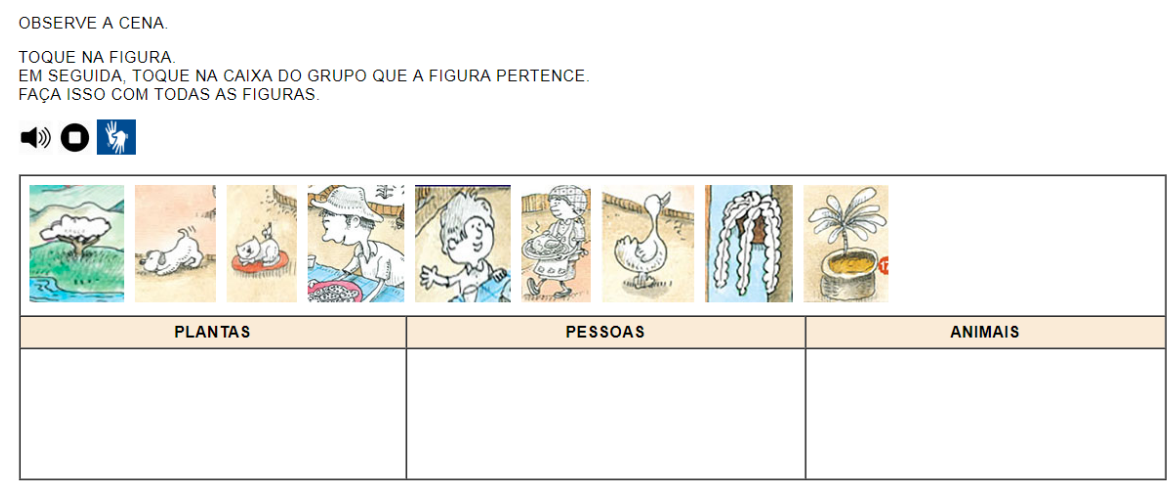

Figura 1. Exemplo de atividade do livro com botões de acessibilidade

capaz de atingir o objetivo sem nenhuma ressalva. Por outro lado, para a equipe de surdos e cegos foram sugeridos algumas alterações, como a utilização de equipamentos maiores (os tablets utilizados tinham telas com 8 polegadas) e que possuam altos-falantes mais potentes, para que as audiodescrições das imagens e a narração do texto fossem ouvidas com mais facilidade.

Todas as equipes acharam o livro útil e concordaram de forma unânime que este trabalho representa um grande avanço na inclusão de alunos com necessidades específicas, principalmente pelo fato de não haver diferenciação curricular.

\begin{tabular}{|c|c|c|c|}
\hline \multicolumn{4}{|c|}{ Dados da aplicação } \\
\hline Deficiência & QTD.Escolas & QTD.Alunos & QTD.Aplicadores \\
\hline Deficiência Auditiva & 1 & 4 & 3 \\
Cegueira e Baixa Visão & 5 & 8 & 9 \\
Autismo & 1 & 4 & 3 \\
Deficiência intelectual & 2 & 5 & 6 \\
\hline
\end{tabular}

Tabela 1. Tabela contendo os dados da aplicação do livro.

\section{Conclusões e Trabalhos Futuros}

Este artigo apresentou a aplicação do conceito Desenho Universal para a Aprendizagem na criação de um protótipo de livro didático digital, O livro foi construído como uma página $H T M L 5$, permitindo a utilização de todos os recursos que uma página Web pode conter, notadamente execução de vídeos e sons embutidos, interatividade através de $J a$ vaScript.

O protótipo foi validado em sessões de aplicação com crianças cegas, com baixa visão, surdas, deficiência intelectual e autismo. Ao final, as equipes trouxeram um retorno valioso sobre a utilização do protótipo e foram dadas sugestões de melhoria, que servirão de base para trabalhos futuros.

\section{Referências}

BRASIL (2008). Política nacional de educação especial na perspectiva da educação inclusiva. In Resolução 4. Brasília. 
VII Congresso Brasileiro de Informática na Educação (CBIE 2018)

Anais do XXIX Simpósio Brasileiro de Informática na Educação (SBIE 2018)

BRASIL (2009). Diretrizes operacionais para o atendimento educacional especializado na educação básica, modalidade educação especial. In Resolução 4. Brasília.

CARVALHO, R. E. (2008). Escola Inclusiva: a reorganização do trabalho pedagógico. Porto Alegre.

CORNÉLIO, S. D. V. (2015). Perspectiva do letramento: mudanças e permanências nos livros didátiicos de alfabetização. In Universidde Federal do Espírito Santo. Vitória.

Mendes, F. R. (2016). Segurança social: O futuro hipotecado. Fundação Francisco Manuel dos Santos.

Pletsch, M. D., Souza, F. F. d., and Orleans, L. F. (2017). A diferenciação curricular e o desenho universal na aprendizagem como princípios para a inclusão escolar. Revista Educação e Cultura Contemporânea, 14(35):264-281.

Rose, D. H. and Gravel, J. W. (2010). Universal design for learning.

SONDERMANN, D. V. C., ALBERNAZ, J. M., and BALDO, Y. P. (2013). Em busca da educação inclusiva na educação a distância: reflexões e possibilidades por meio do universal design for learning. Nuevas Ideas Inform. Educ, pages 300-307.

SOUZA, F.F.;PLETSCH, M. (2017). A relação entre as diretrizes do sistema das nações unidas(onu) e as políticas de educação inclusiva no brasil. In Revista Ensaio:aval. pol. públ. Educ.,v.25. Rio de Janeiro. 